\title{
STOP MOTION COMO SUPORTE NO PROCESSO DE APRENDIZAGEM POR MEIO DAS MÍDIAS
}

\author{
STOP MOTION AS SUPPORT IN THE LEARNING PROCESS THROUGH MEDIA
}

\author{
Ana Clara Lima Rodrigues \\ Professora de matemática da Prefeitura de Nova Iguaçu. Professora do ensino fundamental da SME/RJ. \\ Formadora do PNAIC. Tutora do proletramento de matemática/UFRJ. Mestra em Nova tecnologias Digitais \\ na educação/Unicarioca. \\ https://orcid.org/0000-0002-9232-4429 \\ Verônica Eloi de Almeida \\ Doutora em Sociologia - Núcleo de Pesquisa em Sociologia da Cultura - UFRJ/IFCS. Pesquisadora do \\ Mestrado em novas tecnologias digitais na educação - UNICARIOCA \\ https://orcid.org/0000-0003-4694-8617 \\ André Cotelli do Espírito Santo \\ Colaborador de Projetos no Instituto de Engenharia Nuclear. Professor no Centro Universitário Carioca. \\ Mestre em Ciência e Tecnologia Nucleares pelo IEN \\ https://orcid.org/0000-0002-6593-5259 \\ Data de submissão: 05/05/2020 \\ Data de aprovação: 30/05/2020
}

\section{RESUMO}

As novas tecnologias e todas as transformações sociais delas advindas têm afetado também a educação e os processos de ensino-aprendizagem, fazendo-se necessária a construção de práticas didáticas diversificadas e inovadoras. Nesse contexto, o objetivo deste artigo é apresentar os resultados da aplicação de uma metodologia de uso do Stop Motion em sala de aula, com a observação do percurso metodológico, relato do professor quanto aos efeitos da atividade nos estudantes e discussões sobre a utilização deste suporte na educação. Trata-se de uma metodologia, cujo alicerce empírico se baseia na coleta de dados referentes ao desenvolvimento dos alunos. Constatou-se que o Stop Motion beneficia os estudantes no processo de letramento, favorecendo a construção do pensamento crítico.

Palavras-chave: Educação. Cinema. Audiovisual.

\begin{abstract}
The new technologies and all the social transformations that come from them have affected education and the teaching / learning processes, making it necessary to build diversified and innovative pedagogical practices. In this context, the objective of this article is to present the results of the application of a methodology for using Stop Motion in the classroom, with the observation of the methodological path, the teacher's report on the effects of the activity on students and the discussions on the use of this support in the education. It is a methodology, the empirical foundation of which is based on the collection of data related to the development of students. It was found that Stop Motion benefits students in the literacy process, favoring the construction of critical thinking.
\end{abstract}

Keywords: Education. Movie theater. Audio-visual. 


\section{INTRODUÇÃO}

A utilização do cinema na escola, principalmente na perspectiva de produção, abre caminhos para pensarmos novas formas pedagógicas de incentivar crianças e jovens a se apropriarem das TIC de modo autônomo e criativo, desenvolvendo habilidades que são importantes para o universo escolar, como a alfabetização e o letramento. A relação da escola com a sétima arte tem sido transformada pelas novas tecnologias digitais graças à facilidade que crianças e adolescentes têm para interagir com diversas plataformas, sites e serviços de streaming. De filmes independentes a clássicos de Hollywood, os filmes e outras produções chegam com muito mais facilidade e rapidez nas mãos dessa geração (ARAÚJO; RAMOS; SOUZA, 2012).

Existem várias perspectivas para a abordagem do cinema na educação escolar. As consideradas mais conservadoras defendem o uso dos filmes em sala de aula como ferramenta pedagógica (NAPOLITANO, 2003). Contudo, outras abordagens definem a relação cinema e escola como importante para a construção de sentidos, de valores sociais e alteridade (DUARTE, 2002; FISCHER, 2002; FRESQUET, 2012). O audiovisual e o cinema, compreendidos como arte, são importantes para o processo de construção da alteridade e para diversidade presente no ambiente escolar. É também relevante para o processo de letramento de crianças do primeiro nível do ensino fundamental, e se estende até a capacidade letrada plena.

Com o desenvolvimento da tecnologia, a cultura audiovisual tem ganhado destaque na educação, pois provoca fascínio e familiaridade sobre os jovens, além de ser um potencial de transformação quando aplicada na educação. Por outro lado, cabe reforçar que ela não pode ser tomada como única, no sentido de que sozinha vá modificar as metodologias de ensino-aprendizagem (RIBEIRO JÚNIOR, 2011). Nessa perspectiva, estudos sobre a utilização de oficinas de Stop Motion como ferramenta de ensino e avaliação escolar representam originalidade e contribuem com a discussão tanto do uso das tecnologias nos processos educacionais, quanto com as necessidades de novos olhares para a aprendizagem dos estudantes, o que justifica o presente artigo.

A natureza desta pesquisa tem o ambiente natural como fonte direta dos dados e o pesquisador como principal instrumento; os dados coletados são predominantemente descritivos; a preocupação com o processo é muito maior que com o produto; o significado que as pessoas dão às coisas e à sua vida são focos de atenção especial; e a análise dos dados tende a seguir um processo indutivo. Este estudo, no que toca à sua fundamentação teórica, é baseado em pesquisa qualitativa exploratória, apoiada por uma revisão bibliográfica narrativa. Trata-se de uma metodologia, cujo alicerce empírico, realiza-se sobre a coleta de dados referentes ao desenvolvimento dos alunos no decorrer das oficinas, diretamente dentro das escolas.

O objetivo deste artigo é apresentar os resultados da aplicação de uma metodologia voltada para o uso das técnicas de Stop Motion em sala de aula. No dia 20 de junho de 2018, foi realizada uma oficina com 36 professores de algumas escolas do Rio de Janeiro, das 8 h30 às $11 \mathrm{~h}$ da manhã, ocasião na qual um dos professores presentes prestou-se a concretizar o projeto com seus alunos e aportar as informações relativas às atividades.

A oficina em questão teve como finalidade difundir a utilização do Stop Motion nas escolas, além de mensurar a percepção dos professores acerca da utilização das tecnologias em sala de aula e como ferramenta para o letramento e multiletramento dos estudantes.

No escopo do presente artigo, será analisado o percurso metodológico utilizado com os alunos na situação prática e, ademais, serão apresentados o relato do professor quanto 
aos efeitos da atividade nos próprios estudantes e algumas discussões em torno do cinema na escola, do Stop Motion, da utilização das tecnologias na escola e de como, finalmente, essas oficinas podem se tornar um suporte no processo ensino-aprendizagem.

\section{REFERENCIAL TEÓRICO}

Uma extensa gama de estudos aponta que há interação ativa e relevante do receptor com a programação televisiva e com os filmes de Hollywood. Entretanto, a ideia defendida por Adorno e Horkheimer (1997) difere um pouco dos conceitos existentes. Para os autores, a Indústria Cultural impede a formação de indivíduos autônomos e independentes, capazes de julgar conscientemente o conteúdo apresentado em produtos da televisão e do cinema. Nessa perspectiva, o ser humano é apenas consumidor do negócio lucrativo do audiovisual comercial. A crítica dos autores também recai sobre o mecanismo de produção desses audiovisuais que, nesse contexto, seguem a lógica da indústria na qual a televisão e o cinema hollywoodiano são influências negativas para a sociedade, sobretudo, para as crianças.

Por outro lado, os estudos latino-americanos afirmam que o telespectador consumidor de diferentes tipos de audiovisuais comerciais - tem competência cultural para interagir com esses diferentes formatos e, nesse sentido, é necessário ouvir e atender os consumidores de maneira que também apresentem seus pontos de vista (OROZCO GÓMEZ, 2001; CANCLINI, 2008; MARTIN-BARBERO, 2008). Ou seja, há divergências significativas quanto aos benefícios ou possíveis problemas advindos dos audiovisuais.

Segundo Duarte (2002, p. 86) o cinema se manifesta no ambiente escolar. Quer pelo fato de que ver filmes é prática comum a quase todos os grupos da sociedade, quer porque no meio educacional é possível reconhecer que "o cinema desempenha um papel importante na formação cultural das pessoas". Sob esse ponto de vista, tendo como cenário o contexto atual de ampliação do uso das TIC, refletir e analisar o uso do cinema e do audiovisual no cotidiano e na formação de alunos e professores é fundamental para o desenvolvimento de crianças e jovens.

A animação em Stop Motion é realizada mediante a ilusão de movimento a partir da "captura de diversas fotos do mesmo objeto, entretanto, entre uma fotografia e outra, realizam-se pequenos movimentos ou alterações no objeto ou cenário. Cada imagem registrada é nomeada como quadro" (PAVANELLI-ZUBLER; ZANIN; AYRES, 2016, p. 4).

Dessa forma, pode-se entender que a produção se dá pelos fragmentos das imagens captadas em fotografias, associando sons e texto para o desenvolvimento do vídeo. Além disso, é necessário que a história seja escrita anteriormente de forma objetiva e em poucas linhas, com a noção completa de começo, meio e fim para a narrativa que será desenvolvida. Trata-se de um roteiro, Storyline, que não deverá ultrapassar cinco linhas. E, ainda, antes de iniciar a montagem dos cenários das fotos, caso sejam utilizados, ainda deverá ser preparado o Storyboard, que funciona como uma história em quadrinho, dando a perspectiva de enquadramento, foco das imagens, universo de personagens envolvidos e a própria duração que dar-se-á para a cena, considerando que, como afirma Kaminski (2010), para que a ilusão de movimento seja real e satisfatória, a animação conta com um mínimo de 12 fotogramas por segundo de vídeo.

Cabe acrescentar que há poucos trabalhos desenvolvidos em função do uso do Stop Motion em sala de aula, e, ainda que os autores abordados possam ser entendidos como pouco atuais, o fato é que realmente a utilização da atividade como prática pedagógica não é ampla, nem ao menos no âmbito das discussões acadêmicas. Nesse contexto, como afirmou Rodrigues (2019a, p. 179), 
As transformações ocorridas na sociedade nas últimas décadas, inegavelmente, alcançam a educação e obrigam os atores a uma adaptação nas formas de ensino. $O$ acesso quase irrestrito às tecnologias e o constante uso, em especial, dos aparelhos celulares em sala de aula representa um conflito com o qual os professores necessitam lidar hodiernamente. Aliar o celular como uma ferramenta de aprendizagem, a partir da aplicabilidade da técnica de Stop Motion é uma possibilidade mais atrativa para os estudantes a ser encarada no âmbito da alfabetização, letramento e multiletramento. Escrita, imagem e sons não se separam no desenvolvimento do aprendiz, o que promove a necessidade de percepção da inexistência da monomonalidade na construção plena dos sujeitos, mediante a utilização de meios representacionais diversificados.

Ademais, ainda segundo Rodrigues (2019b, p. 267),

apesar de o cinema e outras mídias como recursos para o letramento serem muito discutidos por escritores e professores, o Stop Motion é um tema muito menos abordado. [...]. É preciso que outras pesquisas e experiências sejam feitas, para que esse recurso lúdico possa ser mais aproveitado no cenário educacional.

É justamente nessa perspectiva que aqui a atenção está voltada para a valorização dessa prática, tanto no que se refere à sua capacidade intrínseca de atrair as crianças para sua própria aprendizagem e o letramento pleno, como para o fato de que é necessário que educadores se atentem para as evoluções tecnológicas e as muitas oportunidades que elas podem trazer consigo.

\section{METODOLOGIA}

\subsection{Sequência Didática da Oficina de Stop Motion}

Para a realização da oficina foram utilizadas cinco aulas de 50 minutos cada uma. Com exceção da segunda aula, as demais foram divididas em momentos distintos. No primeiro momento da aula 1, cuja duração foi de 20 minutos, foi apresentado o projeto aos alunos, explicando sobre a importância da atividade e do uso do audiovisual no processo de aprendizagem. Mostrou-se o aplicativo para celulares e vídeos no YouTube de curtas metragens que utilizam a técnica de Stop Motion. Nesse contexto, o professor pode optar por baixar os vídeos e apresentar por meio de Datashow. Também é nesse momento que o professor apresenta as etapas de produção.

No segundo momento dessa primeira aula, considerando-se também cerca de 20 minutos, deu-se prosseguimento, dividindo a turma em grupos de aproximadamente 4 ou 5 alunos, propondo temas para o trabalho, relacionados com o conteúdo escolar. É interessante que os estudantes realizem a atividade em torno de alguma temática que ainda não foi apresentada em sala, portanto, um tema novo, pois isso tende a explorar o instinto investigativo do aluno e a aguçar sua curiosidade no processo de aprendizagem; embora não seja também um equívoco realizar a atividade após algum assunto específico e, nessa situação, propõe-se a atividade para aprofundamento e internalização. No caso do trabalho realizado pelo professor de geografia, cujo relato será analisado na sequência, escolheuse como tema a poluição das águas e o desmatamento. Os assuntos ainda não tinham sido tratados em sala.

A segunda aula foi dada como livre, para que os alunos pesquisassem em sala sobre o tema escolhido, utilizando a internet a partir de aparelhos celulares ou, no caso de escolas que possuem salas de computador, os alunos poderiam optar por modificar o ambiente interativo se deslocando para as salas computadorizadas. É bom que a pesquisa seja feita em sala e com a utilização de meios digitais, haja vista que se pretende gerar aproximação entre o estudante, as tecnologias e a escola. 
O primeiro momento da terceira aula, de aproximadamente 20 minutos, foi dedicado a baixar o programa nos celulares dos próprios alunos. O normal é que eles mesmos tenham autonomia para tanto. Há diversos programas que realizam a edição de vídeos, mas é ideal que todos utilizem o mesmo programa, por questões de critérios formais. Foi utilizado o aplicativo Minecraft Stop-Motion Movie Creator. No segundo momento, houve a produção do Storyline; ou seja, os alunos discutiram a sequência da história e escreveram o texto, narrando as cenas que seriam gravadas. Nessa etapa, também determinaram as características das personagens e do cenário.

No primeiro momento da quarta aula, durante cerca de 20 minutos, aconteceu a produção do Storyboard, resumo em quadrinhos sobre as cenas do curta. Nessa etapa, tem-se o desenvolvimento da imaginação, leitura e escrita. O Storyboard deve possibilitar uma noção prévia de como será a animação.

No segundo momento, iniciou-se a preparação dos cenários das maquetes e dos tripés adaptados para que não houvesse movimentação do aparelho celular nas fotografias.

No primeiro momento da quinta aula, foram concluídos os cenários e todas as etapas anteriores, para, em seguida, partirem para a realização das fotos e edição do vídeo, considerando também música e créditos.

Figura 1 - Oficina de Stop Motion

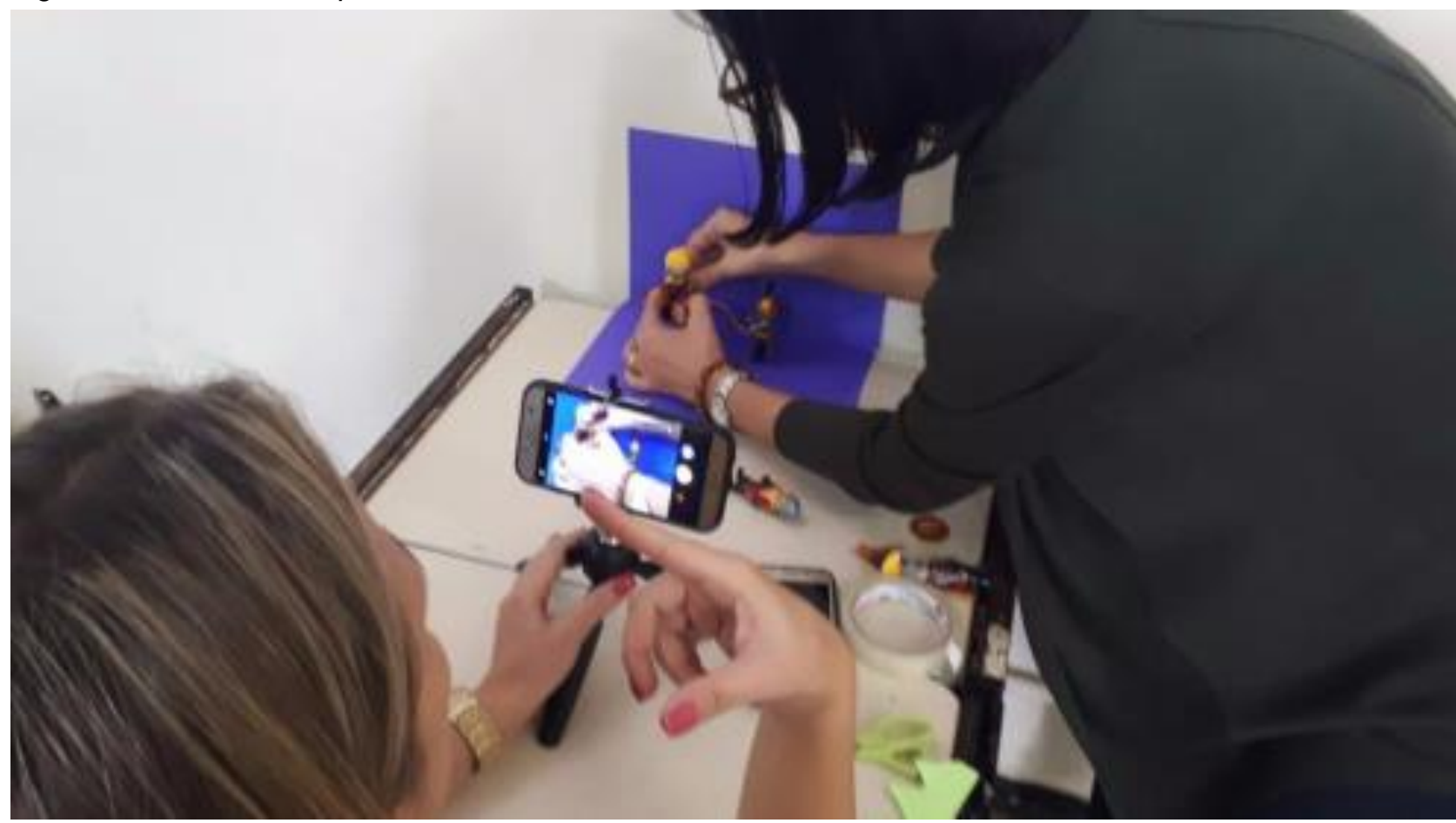

Fonte: Elaborado pelo autor (2018).

O objetivo da sequência didática estabelecida é alcançar professores de quaisquer disciplinas, embora, nesse contexto, seja utilizado um tema proposto em especial no âmbito da geografia.

O perfil de atividades pode ser o mesmo para qualquer disciplina, e o tempo proposto também é manejável; ou seja, não existe intenção de impor uma forma de trabalho ao professor, e, certamente, deve-se considerar as adaptações necessárias ao meio, aos estudantes com os quais se atua, às condições dos recursos, entre outros fatores.

Nesta sequência, foram separados os momentos dentro das aulas, cada uma considerando-se 40 minutos de duração, devido ao fato de que em sala de aula não se tem 
os 50 minutos efetivamente, também por causa do tempo de trânsito do professor de uma sala a outra. Dessa forma, cada aula separada para a atividade ocupará aproximadamente 40 minutos.

Ressalte-se que a animação utilizando o Stop Motion é facilmente realizável, especialmente porque pode ser concretizada por meio de recursos de custo baixo, como papel e canetas, massa de modelar, ou até mesmo o próprio quadro da sala de aula. É uma atividade que possibilita grande flexibilidade e a criação de técnicas e estilos muito diferenciados, seguindo o padrão de cada grupo ou pessoa que edita e cria as cenas (SHAW, 2012).

Após a quinta aula, pode-se realizar um pequeno festival apresentando todos os vídeos produzidos, e, inclusive, realizar uma demonstração de grupos de salas diferentes. Como as produções são curtas, é possível na mesma aula fazer as demonstrações e abordar o tema de forma mais pragmática, ou por meio de um debate, aportando novas informações e discutindo sobre o que os alunos aprenderam. Além disso, existe a possibilidade de realizar um projeto interdisciplinar com assuntos semelhantes para uma amostra de vídeos mais global, que alcance toda a escola.

\section{ANÁLISE E DISCUSSÃO DOS RESULTADOS}

\subsection{Relato Docente após o Uso do Stop Motion em Sala de Aula}

O professor que se prontificou a realizar a oficina e trazer os resultados optou por trabalhar o tema da sustentabilidade, em especial, os cuidados com a água.

O tema de sustentabilidade e água foi escolhido por ser componente da grade curricular, mas, conforme as palavras do professor, "a sustentabilidade não trabalha só o meio ambiente, além de ser abordada nas ciências da natureza, o tema apresenta questões filosóficas e sociológicas pertinentes à nossa sociedade de consumo".

Os estudantes não conheciam a técnica do Stop Motion, e lhes foi explicado acerca da importância de criação do Storyline e Storyboard, que seriam construídos.

O professor relatou que a maioria dos alunos foi capaz de demonstrar com clareza o universo dos personagens, os enquadramentos e a duração da cena proposta por eles, sendo que, ainda, os estudantes foram capazes de contar a história de forma escrita, dividindo-a também em cenas.

As imagens para criação do Stop Motion foram realizadas com a utilização do quadro branco e de caneta própria, com desenhos em 2D, além de recortes de papel e utilização de cartolinas coloridas.

O professor criou os tripés adaptados com garrafas Pet, que os próprios estudantes levaram para a escola, além dos pregadores de papel, celulares, as cartolinas coloridas, e, ainda, foi usada a estrutura de metal de uma carteira velha, servindo de suporte para o celular e criação de cenário.

Segundo o relato do professor, a quantidade de celulares disponíveis para baixar o aplicativo utilizado foi "mais que suficiente".

A conexão e acesso à internet interferiu no processo de realização das atividades. Não havia disponibilidade de conexão na escola, e, em alguns casos, o professor declarou: "Tive que rotear o sinal da internet do meu aparelho celular para baixar o aplicativo". 
Figura 2 - Utilização de Pet como tripé

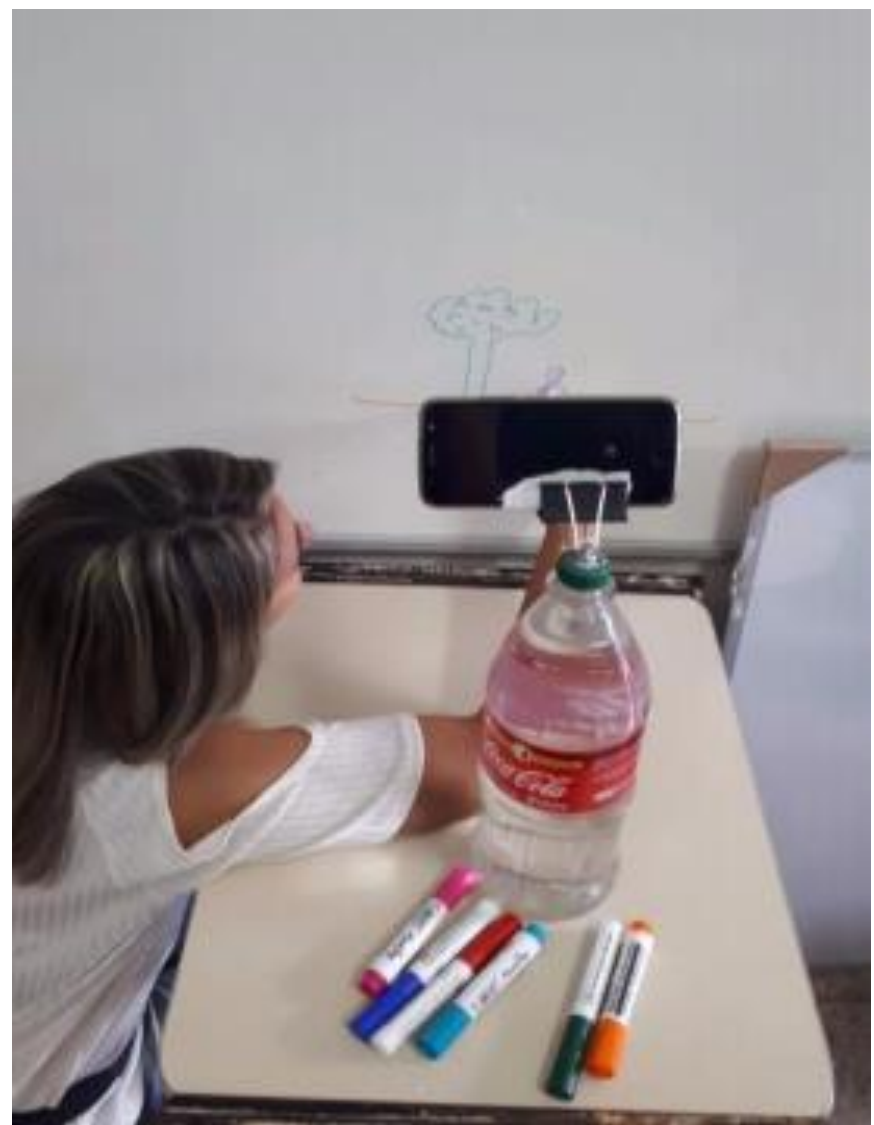

Fonte: Elaborado pelo autor (2018).

Acerca da reação dos estudantes diante da atividade proposta, o professor afirmou que todos os alunos se mostraram interessados e envolvidos, especialmente a partir dos primeiros resultados.

Figura 3 - Construção de cenário com os alunos

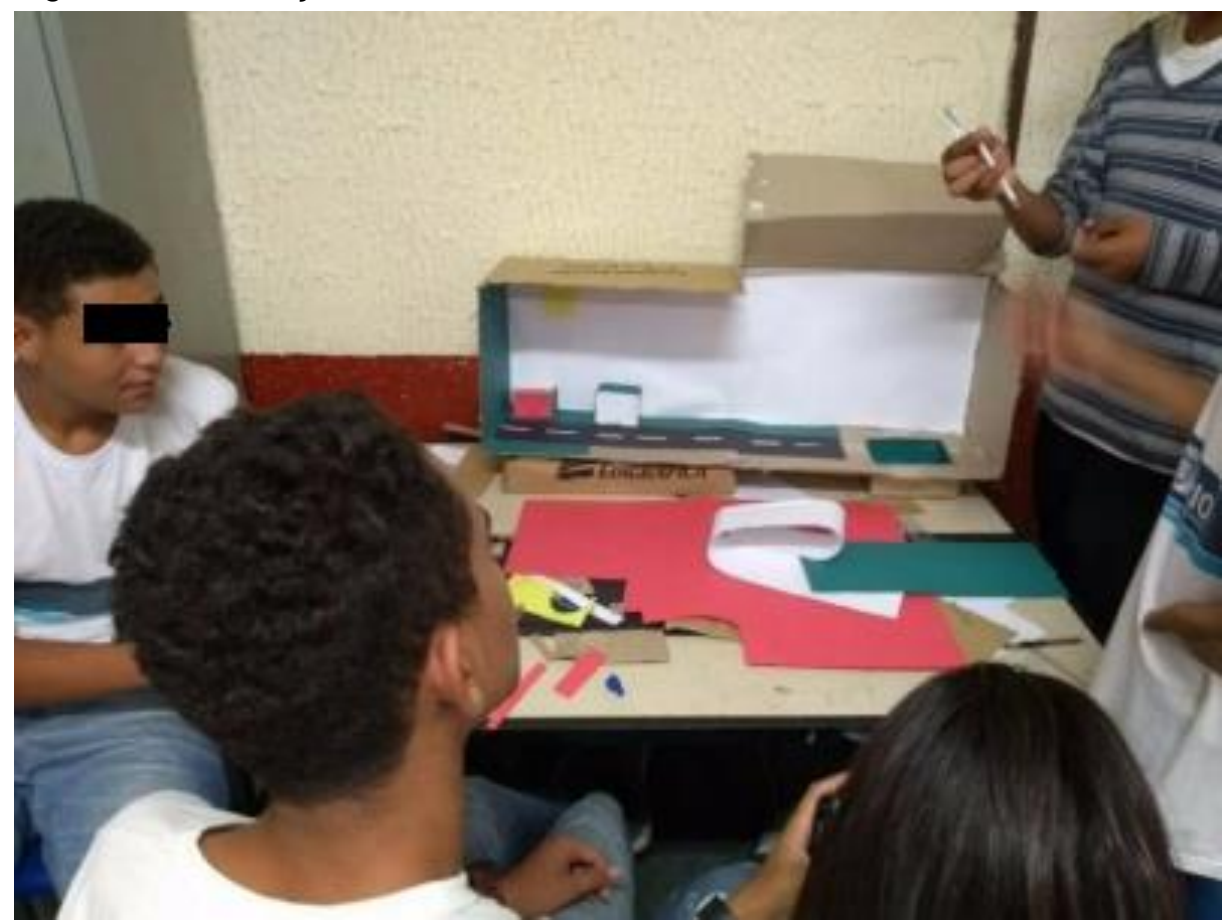

Fonte: Elaborado pelo autor (2018). 
Antes da oficina, o professor havia realizado uma prova escrita, que Ihe permitiu avaliar o nível de letramento nas áreas de Ciências, História, Geografia, Matemática e Língua Portuguesa de cada aluno, envolvendo a capacidade de construção de sentidos por parte dos estudantes.

Após a realização da atividade de Stop Motion, o professor percebeu, através dos debates em sala, que houve aumento de interesse por assuntos que antes não os atraía, além de melhoria significativa nas avaliações.

Conforme o educador, ademais, "eles passaram a ser mais questionadores, a se apropriar do espaço da escola, inclusive com abordagem, no intervalo, aos alunos de outras turmas que praticavam atitudes inapropriadas, como jogar lixo no chão". Isso representou, para o professor, promoção do pensamento crítico dos alunos com relação ao tema estipulado para o trabalho.

Sobre a possibilidade de evolução ou diferença na discussão relativa ao tema antes e após a realização da atividade de Stop Motion, o professor afirmou que os estudantes "levantaram questionamentos sobre o próprio local onde residem, fazendo críticas a respeito de como a sociedade lida com o assunto meio ambiente".

Como professor, pensando não apenas no lúdico proporcionado pela atividade de Stop Motion, mas também na aprendizagem, o educador, em termos do desenvolvimento cognitivo e sociocultural dos alunos, declarou que "eles tiveram que fazer um trabalho colaborativo, trabalho em grupo, e cada um teve sua aptidão valorizada, aquele que sabia organizar melhor o espaço, que sabia desenhar melhor, o que controlava o tempo, a luz, houve trocas de conhecimentos e consequentemente o aprendizado significativo, porque a atividade fazia sentido para os mesmos."

O professor acredita que a atividade tenha ajudado os alunos a compreender melhor o mundo, especialmente no que se refere ao tema proposto, a partir da atividade realizada com Stop Motion. Essa melhora de compreensão se deveria ao fato de que "durante a atividade tiveram que usar sua capacidade crítica e os fatos observados no seu cotidiano para criarem o filme". Além disso, foi bastante significativa a análise que fizeram das atitudes dos personagens e das consequências dessas atitudes.

Segundo o professor, foi possível relacionar, durante a aplicação das atividades, outras disciplinas e não somente a Geografia, uma vez que "trabalharam produção textual com a criação do Storyline e Storyboard, a Matemática através da proporcionalidade dos objetos, Ciências com os ecossistemas, a Geografia também com o conceito de espaço geográfico e paisagem". 


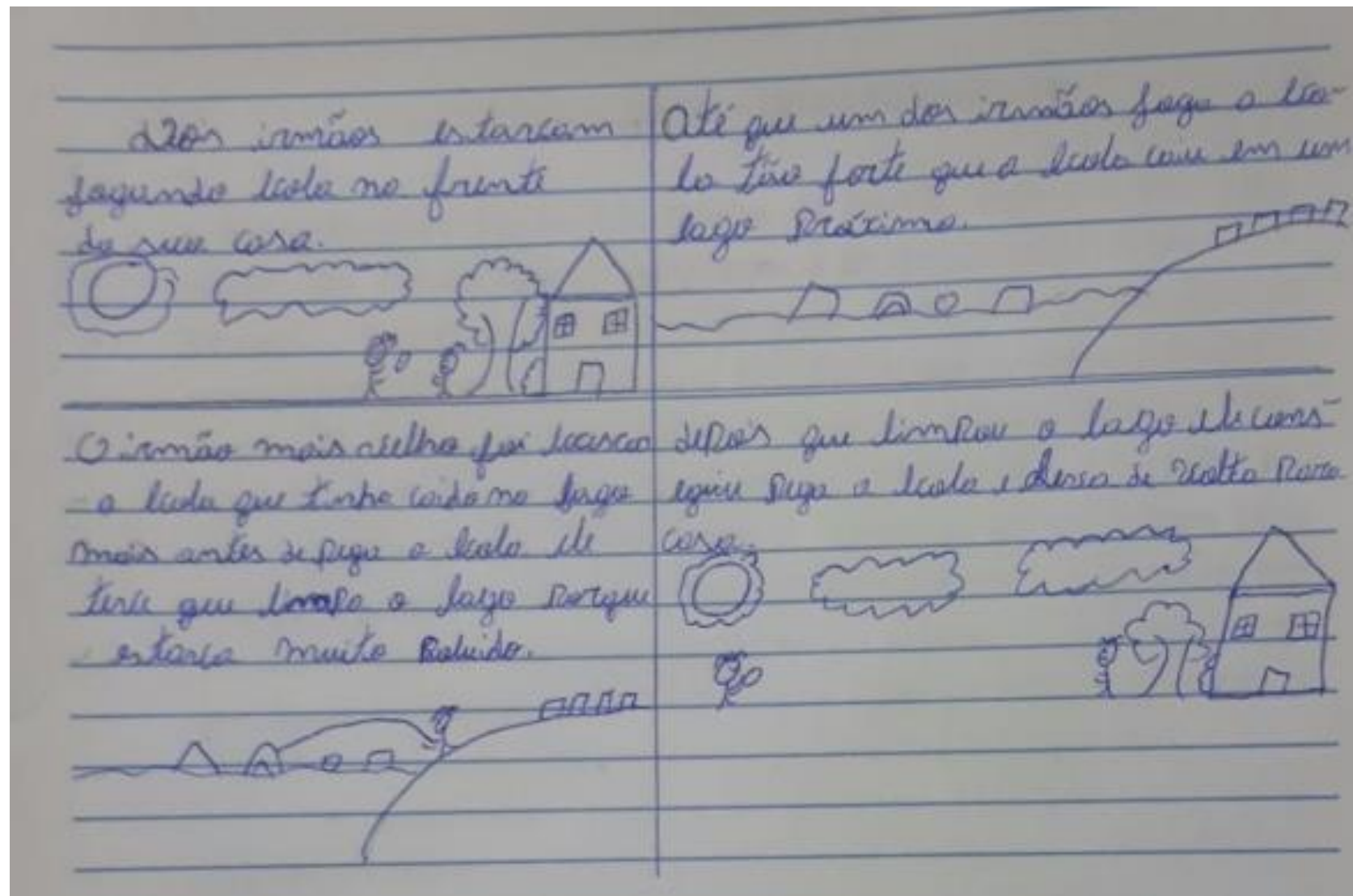

Fonte: Elaborado pelo autor (2018).

Ademais, o maior obstáculo para a realização da atividade foi a "falta de internet na escola para baixar o programa, pois o restante dos materiais utilizados foram adaptações sem custos", o que levou o professor a considerar a atividade de Stop Motion duplicável em todos os níveis de ensino. declaram que

Sobre a utilização da mídia em sala de aula, Bévort e Belloni (2009, p. 1083),

[...] as mídias são importantes e sofisticados dispositivos técnicos de comunicação que atuam em muitas esferas da vida social, não apenas com funções efetivas de controle social (político, ideológico...), mas também gerando novos modos de perceber a realidade, de aprender, de produzir e difundir conhecimentos e informações.

Essa afirmação coaduna com as proposições do professor de Geografia participante da pesquisa, abordando as atividades aplicadas em sala de aula com o Stop Motion. Devese recordar que ele próprio declarou que a prática proposta neste trabalho de pesquisa fez com que os estudantes levantassem questionamentos em torno do meio, da sociedade, posicionando-se criticamente até mesmo com os colegas que jogavam lixo em locais inapropriados dentro da escola, além de questionarem a postura das pessoas na sociedade e como essa sociedade atua com relação ao meio ambiente. É importante ressaltar que, após a oficina, 25 professores afirmaram acreditar que se trata de uma prática emancipatória, e, igualmente, a maioria acredita que se trata de uma atividade lúdica e pedagógica que promove o letramento, mesmo que tenha havido contradições acerca do conceito de letramento e alfabetização.

Nesse aspecto, recordamos as palavras de Soares (1998, p. 40), que afirmou acerca do letrado que "o indivíduo que vive em estado de letramento, é não só aquele que sabe ler 
e escrever, mas aquele que usa socialmente a leitura e a escrita, pratica a leitura e a escrita, responde adequadamente às demandas sociais de leitura e de escrita". Muitos professores, parecem ter se confundido com as definições de alfabetização e letramento, com a utilização social da leitura e da escrita. Mesmo nessa situação, mesmo diante da confusão acerca dos conceitos, os professores, em sua maioria, entenderam o Stop Motion como uma atividade capaz de promover essa interação social dos estudantes, o que, em si, significa o letramento, e confirma a hipótese da utilização da técnica no processo de aprendizagem e letramento estudantil, a fim de se criar cidadãos mais críticos e engajados com o meio em que vivem, menos alienados, mais capazes de respeitar as diferenças e mais colaborativos.

A colaboração e o respeito a essas diferenças foi relatada pelo professor de Geografia, quem afirmou que as multiplicidades de aptidões foram respeitadas e valorizadas, já que um sabia desenhar melhor, o outro escrever, o outro era mais criativo, e, dessa forma, o trabalho em equipe abrangeu de maneira satisfatória os estudantes, envolvendo-os profundamente no tema que estava sendo trabalhado, na medida em que todos se fizeram importantes no processo. Isso, por sua vez, também promoveu o pensamento crítico e o engajamento social dos alunos.

$\mathrm{Na}$ realização da atividade, os jovens tiveram que colaborar com materiais, mas, principalmente, com suas habilidades particulares em prol do trabalho do grupo. Isso foi um diferencial que minimizou a importância dos obstáculos que poderiam se levantar. Foi possível observar que os recursos para a realização da atividade na escola eram poucos, e poucos foram utilizados, mas isso não tornou a atividade inviável. O maior obstáculo observado foi a falta de acesso à internet na escola.

A internet é fundamental no processo educativo atualmente, e, como foi apontado por Santaella (2003), a tecnologia não pode ser resumida a um determinado aparelho ou uma determinada ferramenta, mas também aos modos que se percebe a linguagem e sua utilização, à sensibilidade que se assume perante a escrita. A superação dos obstáculos seria proveitosa, como foi feito pelo professor de Geografia, fazendo com que as atividades realizadas na escola sejam prazerosas e atrativas para os estudantes, o que também acaba implicando o uso das TIC, que fazem parte do universo das novas gerações.

O uso das tecnologias representa a expressão de identidades, conforme Buzato (2001), e, ademais, permite a dinâmica troca de tempos e espaços culturais propostos por Santaella (2003), considerando-se, sobretudo, como afirmou Cardoso (2013, p. 36), que "os media não são a mensagem, mas que as pessoas são a mensagem", as tecnologias utilizadas não resumem a mensagem transmitida, mas, mediante a modificação que provoca nas pessoas, torna as pessoas a própria mensagem. No contexto do Stop Motion (e das atividades realizadas), os alunos tornam-se as mensagens que transmitem, ao mesmo passo que se apropriam dessas mensagens.

Nessa perspectiva, pode-se perceber que nos resultados da presente investigação existem coincidências como o que afirmaram Araújo, Ramos e Souza (2012): que utilizar o cinema no processo educativo, especialmente produzir cinema, abre caminhos dentro da própria pedagogia, capazes de incentivar os estudantes tanto a se apropriarem das TIC, quanto a desenvolverem suas habilidades no universo escolar e no mundo.

Daí a necessidade de se perceber que a função da escola é complexa, ampla e diversificada perante os diferentes contextos sociais. Uma das funções sociais da escola, como apontou Chevallard (1991), é estabelecer mecanismos e estratégias didáticas que possam oportunizar o saber científico, por meio da transposição didática do conhecimento escolar. Ao professor não cabe transmitir conhecimentos, mas facilitar e mediar a construção do conhecimento científico de forma significativa, permitindo ao aluno relacionar 
e correlacionar esses conhecimentos para sua aplicação no contexto social. Essa aplicação no contexto social foi demonstrada na realização da oficina do professor de Geografia, especialmente porque os estudantes aplicaram o que tinham elaborado, interferindo socialmente no ambiente escolar, questionando sobre o lixo e o comportamento social dos demais alunos.

A escola, frente às transformações tecnológicas, deve reestruturar as práticas pedagógicas e os recursos que contribuem significativamente na formação do educando. Essa reestruturação não necessariamente carece de grandes recursos financeiros, mas da capacidade adaptativa de professores e alunos, contando com a colaboração de todos, como aconteceu na realização do Stop Motion com os alunos do professor de Geografia. O ensino de diversas disciplinas pode ser repensado em uma prática que envolve muitos aspectos metodológicos, possibilitando o desenvolvimento do conhecimento escolar. A prática pedagógica é essencial para o desenvolvimento da aprendizagem e 0 aperfeiçoamento na construção do conhecimento em diversas áreas. Assim, é necessário que a escola adote recursos pedagógicos, que proporcionem a apropriação do conhecimento escolar, a fim de que os educandos, no decorrer do processo, apropriem-se de um conhecimento significativo para as suas vidas.

Portanto, compreende-se quão importante é o papel da escola como mediadora entre conteúdo digital e aluno. Entendendo a mídia como um recurso lúdico, pedagogos e professores podem se utilizar dela para tornar as aulas mais prazerosas para os que as assistem. É necessário que o educador veja essas novas ferramentas como aliadas, e que seja capaz de interpretá-las. Recordando os apontamentos de Franco e Lopes (2004), as instituições de ensino não devem entrar em competição com as mídias, mas se associar a elas, criar jogos de comunicação com elas. Essa, basicamente, foi a sustentação da proposta do presente trabalho: interpretar as mídias e as possibilidades oferecidas por elas, a fim de atrair o estudante e levá-lo a interagir na construção do seu próprio saber.

Trata-se de uma prática que atua sobre a coevolução da linguagem e da representação visual, uma vez que letras, sons e imagens se mostram inseparáveis, conforme apontou Lemke (2002) acerca desse processo de evolução em torno do letramento. Além disso, a alfabetização não tem significação quando é desenvolvida à parte dos contextos sociais, mas quando associada a ele, acaba por levar ao letramento, segundo declarou Soares (2004).

Todos esses pontos também levam à observação de que o jogo de linguagem e representação visual estabelecido com o Stop Motion, associado ao contexto social de determinado conteúdo escolar, promove o letramento, e deve-se considerar que o próprio letramento implica, como apontado também por Soares (1998), atuação na interação com linguagens diferentes, audiovisuais, gestuais, dentre outras.

Isso, igualmente, leva-nos ao que Medeiros (2014) considerou como uma influência sobre as novas relações do indivíduo com a sociedade. A interação com os meios digitais amplia as habilidades do sujeito leitor, conforme acrescentou Coscarelli (2009), que passa a ler não somente o texto, mas o mundo que o cerca. Na medida em que os estudantes precisam aprofundar no tema proposto pelo professor, precisam criar Storyline e Storyboard, precisam desenvolver habilidades conjuntas, a interação acontece e o conhecimento é assimilado com maior profundidade, interferindo nas concepções que os sujeitos assumem no seu dia a dia, repensando a própria sociedade e suas posturas, como foi relatado pelo professor de Geografia, a partir de sua observação de como os alunos começaram a questionar e discutir assuntos que antes pareciam não despertar interesse.

Por outro lado, as relações intersemióticas apontadas por Kress (2010) no processo de multiletramento, associando escrita, imagem, cores, etc., podem ser entendidas como a 
própria comunicação humana, a partir da reelaboração e rearticulação da representação que os indivíduos fazem da sociedade, levando à produção e reprodução de significados abordadas por Cope e Kalantzis (2009). Esse multiletramento proporcionado pelo Stop Motion envolve o processo social do letramento, as práticas diferenciadas que minimizam a alienação ideológica, e a ampliação de percepções por meios diversificados, apoiandose, ainda, no que Rojo (2009) chamou de tolerância às diversidades.

Considere-se, ainda, que o Stop Motion pode ser utilizado no processo avaliativo dos alunos, especialmente porque os métodos avaliativos buscam mensurar o conhecimento do aluno, e, na medida em que essa atividade se mostrou capaz de aportar ao professor referenciais do desenvolvimento cognitivo do estudante, pode ser utilizada também como ferramenta de avaliação. Nesse sentido, vale a pena recordar que Luckesi (2011) declarou a capacidade de assimilação dos conteúdos a partir da realização do Stop Motion, e afirmou que com a avaliação subsidia as decisões que o professor toma acerca da mensuração dessa absorção de conhecimentos, a qualidade do próprio conteúdo demonstrado nos vídeos serve de parâmetro para avaliação. Além disso, Vasconcellos (2003) apontou para o fato de que avaliar os estudantes por meio de técnicas diferenciadas, permite que eles tenham mais momentos de aprendizagem durante a avaliação, expressando melhor seus domínios.

Acredita-se que a utilização da técnica da animação Stop Motion, como forma de avaliação, pode fazer com que o aluno assimile os conteúdos trabalhados e demonstre na prática o que aprendeu. A avaliação, como afirmou Luckesi (2011), subsidia decisões a respeito da aprendizagem dos educandos, tendo em vista garantir a qualidade do resultado construído. Assim, a proposta de avaliar os alunos com a técnica, permite que eles tenham, na avaliação, mais um momento de aprendizagem, no qual expressarão o que realmente dominam. O que diferencia essa técnica é o posicionamento do aluno frente ao processo educativo, demonstrando seus valores e habilidades, despertando-os para o desejo de aprender. Isto é relevante, pois alguns professores acreditam que o aluno deveria ter interesse em estudar, mas a necessidade de despertar essa motivação parte também das atribuições do educador.

\section{CONSIDERAÇOES FINAIS}

A partir da realização da oficina com os professores e dos questionários por eles respondidos, foi possível identificar as concepções dos educadores acerca da influência das mídias, do cinema e do Stop Motion, no processo de letramento e multiletramento. Constatou-se que há uma distorção de conceitos, mas, ainda assim, a maioria dos professores entende a importância da utilização das mídias no processo educacional, utilizando-se de projeções de vídeos, áudio, etc., para ilustrar ou complementar o conhecimento que já havia sido transmitido ou como introdução de algum conteúdo. Já se pode notar que o professor não atua como como transmissor do conhecimento, mas como mediador, como alguém que deve estimular a aprendizagem e o aprender a aprender. Tal postura foi percebida na maioria dos professores que participaram da oficina.

Essa oficina foi ainda mais produtiva do que o esperado, haja vista que, na ocasião, um professor participante se ofereceu para realizar a atividade com seus alunos e fornecer informações de suas observações com relação ao comportamento dos estudantes e a influência do Stop Motion com o nível de letramento dos jovens. Pelo que foi reportado pelo professor e pelo que a literatura acerca do tema mostrou, foi possível averiguar a viabilidade e os benefícios da utilização da prática de Stop Motion com alunos do Ensino Fundamental, recordando que o professor de Geografia declarou que a prática pode ser realizada em qualquer nível de ensino. 
Considera-se cumprido o objetivo geral deste trabalho, que foi apresentar os resultados da aplicação de uma metodologia voltada para o uso das técnicas de Stop Motion em sala de aula. Foi exposto o percurso metodológico utilizado com os alunos em sala de aula, além do relato do professor acerca dos efeitos da atividade sobre os próprios estudantes, e, finalmente, discutiu-se em torno do cinema na escola, do Stop Motion, das TIC e das mídias na escola, demonstrando-se como esse tipo de atividade pode se tornar um suporte no processo ensino-aprendizagem.

Diante de todos os levantamentos e exposições, parece bastante evidente o quanto - Stop Motion pode beneficiar os estudantes em seu processo de letramento e multiletramento, envolvendo os alunos no contexto social e favorecendo a construção de cidadãos portadores de pensamento crítico-reflexivo-transformador, objetivo maior da educação. Podendo, ainda, serem inseridas nos processos avaliativos escolares, na medida em que os professores podem observar e captar as mudanças das posturas críticas dos estudantes dentro do contexto social no qual estão inseridos.

Espera-se que este trabalho possa trazer contribuições para os educadores, e que, socialmente, possa promover, a partir desses atores tão especiais da sociedade, a construção de cidadãos mais participativos e preparados para a vida adulta, mediante sua interação com seu próprio desenvolvimento.

\section{REFERÊNCIAS}

ADORNO, T. W.; HORKHEIMER, M. Dialética do esclarecimento. Tradução de Guido Antônio de Almeida. Rio de Janeiro: Jorge Zahar Editor, 1997.

ARAÚJO, R. D. de; RAMOS, M. A. M.; SOUZA, A. C. B. de. Cinema e educação:

Reflexões teórico-metodológicas e didáticas. In: FIPED - FÓRUM INTERNACIONAL DE PEDAGOGIA, 4, 2012, Paraíba, Campina Grande. Realize Editora, 2012. Disponível em: <http://www.editorarealize.com.br/revistas/fiped/trabalhos/ed72f80c15975b7dee45e8697d be1f53_58.pdf> Acesso em 18 jun. 2018.

BÉVORT, E.; BELLONI, M. L. Mídia-educação: Conceitos, história e perspectivas. Educ. Soc., Campinas, v 30, n. 109, p. 1081-1102, 2009. Disponível em: <http://www.scielo.br/pdf/es/v30n109/v30n109a08.pdf> Acesso em 18 jun. 2018.

BUZATO, M. E. K. Letramentos digitais e formação de professores. Campinas: IEL / UNICAMP, 2001.

CANCLINI, N. G. Leitores, espectadores e internautas. São Paulo: lluminuras, 2008.

CARDOSO, G. Para além da internet e dos Mass Media. In Sociedade dos Ecrãs.

CARDOSO, G. (org.). Lisboa: Tinta da China, 2013.

CHEVALLARD, Y. La tranposición didáctica: del saber sabio al saber enseñado.

Traduzida por Claudia Gilman. Buenos Aires: Aique, 1991.

COPE, B.; KALANTZIS, M. (orgs.). A grammar of multimodality. International journal of Learning, v.16, n. 2, p. 361-425, 2009. Disponível em:

<http://newlearningonline.com/_uploads/L09_17649_MultImodalGrammar_final.pdf> Acesso em 18 jun. 2018.

COSCARELLI, C. V. Textos e hipertextos: Procurando o equilíbrio. Linguagem em (Dis)curso, Palhoça, SC, v.9, n.3, p. 549-564, 2009. Disponível em: <http://www.scielo.br/pdf/ld/v9n3/06.pdf> Acesso em: 18 jun. 2018.

DUARTE, R. Cinema \& Educação. Belo Horizonte: Autêntica, 2002. 
FISCHER, R. M. B. O dispositivo pedagógico da mídia: modos de educar na (e pela) TV. Educação e Pesquisa, [S.I], v. 28, n. 1, 2002. Disponível em:

$<$ http://www.scielo.br/scielo.php?pid=S1517-

97022002000100011\&script=sci_abstract\&tIng=es> Acesso em 25 jun. 2018.

FRANCO, J. F.; LOPES, R. de D. Novas tecnologias em ambientes de aprendizagem; estimulando o aprender a aprender, transformando o currículo e ações. RENOTE -

Revista Novas Tecnologias na Educação, 2004. Disponível em: <

https://seer.ufrgs.br/renote/article/view/13754> Acesso em 22 jun. 2018.

FRESQUET, A. Dossiê cinema e educação, uma ralação sob a hipótese de alteridade (segunda parte). Revista Contemporânea de Educação, [S.I.], v. 5, n. 10, fev. 2012. Disponível em: <https://revistas.ufrj.br/index.php/rce/article/view/1596> Acesso em: 10 ago. 2018.

KAMINSKI, V. R. Animação no Ensino Fundamental: Stop Motion. UEPG Universidade Estadual de Ponta Grossa. Ponta Grossa: UEPG, 2010. Disponível em: <http://www.fap.pr.gov.br/arquivos/File/extensao/2-ENREFAEB_3-SimposioAV/15ValeriaRaquelKaminski.pdf> Acesso em: 28 fev. 2018.

KRESS, G. Multimodality: a social semiotic approach to contemporary communication. USA/Canada: Routledge, 2010.

LEMKE, J. L. Travels in hypermodality. Visual Communication, v. 1, n. 3, London, Thousand Oaks, CA and New Delhi, p. 299-325, 2002. Disponível em: <http://journals.sagepub.com/doi/pdf/10.1177/147035720200100303> Acesso em: 18 jun. 2018.

LUCKESI, C. C. Avaliação da aprendizagem: componente do ato pedagógico. São Paulo. Cortez, 2011.

MARTIN-BARBERO, J. Dos meios às mediações: comunicação, cultura e hegemonia. 5.ed. Rio de Janeiro: UFRJ, 2008.

MEDEIROS, Z. Gêneros, multimodalidade e letramentos. RBLA, Belo Horizonte, v. 14, n. 3, p. 581-612, 2014. Disponível em: <http://www.scielo.br/pdf/rbla/v14n3/a05v14n3.pdf> Acesso em: 18 jun. 2018.

NAPOLITANO, M. Como usar o cinema na sala de aula. São Paulo: Contexto, 2003. OROZCO GÓMEZ, G. Television, audiências y educacion. Buenos Aires: Norma Editorial, 2001.

PAVANELLI-ZUBLER, É. P.; ZANIN, J. L.; AYRES, S. R. B. Stop Motion: Formação Continuada para seu Uso no Processo de Ensino e Aprendizagem. In: Seminário de Educação, Tecnologia e Sociedade, 21, Núcleo de Educação On-line. FACCAT Faculdades Integradas de Taquara. FACCAT, 2016. Disponível em: <https://seer.faccat.br/index.php/redin/article/download/450/373>. Acesso em: 28 fev. 2018.

RIBEIRO JUNIOR, D. O Audiovisual na Escola: Dominação ou Transformação. Revista Universitária do Audiovisual, São Carlos, 15 mar., p 1-7 2011. Disponível em: <http://www.rua.ufscar.br/o-audiovisual-na-escola-dominacao-ou-transformacao/> Acesso em: 28 fev. 2018.

RODRIGUES, A. C. L. Processos de Aprendizagem: o Auxílio das Mídias Digitais e a Realização da Prática de Stop Motion em Sala de Aula. Revista Ensino, Educação e Ciências Humanas, v. 20, n. 2, p. 170-180, 2019. 
RODRIGUES, A. C. L. Uso das tecnologias na escola: Stop Motion como ferramenta de ensino e aprendizagem. Revista Educação Popular, v. 18, n. 2, p. 252-269, maio/ago. 2019.

ROJO, R. H. R. Letramentos múltiplos, escola e inclusão social. São Paulo: Parábola, 2009.

SHAW, S. Stop motion: técnicas manuais para animação com modelos. Rio de Janeiro: Campus Elsevier, 2012. (Media Technology)

SANTAELLA, L. Culturas e artes do pós-humano: da cultura das mídias à cibercultura. São Paulo: Paulus, 2003.

SOARES, M. Letramento: um tema em três gêneros. Belo Horizonte: Autêntica, 1998. SOARES, M. Letramento e alfabetização: as muitas facetas. Revista Brasileira de Educação, n. 25, p. 5-17, 2004. Disponível em:

<http://www.scielo.br/pdf/\%0D/rbedu/n25/n25a01.pdf> Acesso em: 18 jun. 2018.

VASCONCELLOS, C. dos S. Avaliação da aprendizagem: práticas de mudança: por uma práxis transformadora. São Paulo: Libertad, 2003. 